\title{
Sex Differences in Maturation and Attrition of Adult Neurogenesis in the Hippocampus
}

\author{
Shunya Yagi,, ${ }^{1,4}$ Jared E.J. Splinter, ${ }^{3,4}$ Daria Tai, ${ }^{2}$ Sarah Wong, ${ }^{2,4}$ Yanhua Wen, ${ }^{2,4}$ and \\ (Diisa A.M. Galea ${ }^{1,2,4}$
}

https://doi.org/10.1523/ENEURO.0468-19.2020

\begin{abstract}
${ }^{1}$ Graduate Program in Neuroscience, University of British Columbia, Vancouver, British Columbia V6T 1Z3, Canada, ${ }^{2}$ Department of Psychology, University of British Columbia, Vancouver, British Columbia V6T 1Z3, Canada,

${ }^{3}$ Department of Physics and Astronomy, University of British Columbia, Vancouver, British Columbia V6T 1Z3, Canada, and ${ }^{4}$ Djavad Mowafaghian Centre for Brain Health, University of British Columbia, Vancouver, British Columbia V6T 1Z3, Canada
\end{abstract}

\begin{abstract}
Sex differences exist in the regulation of adult neurogenesis in the hippocampus in response to hormones and cognitive training. Here, we investigated the trajectory and maturation rate of adult-born neurons in the dentate gyrus (DG) of male and female rats. Sprague Dawley rats were perfused $2 \mathrm{~h}, 24 \mathrm{~h}$, one week (1w), $2 \mathrm{w}$, or $3 \mathrm{w}$ after bromodeoxyuridine (BrdU) injection, a DNA synthesis marker that labels dividing progenitor cells and their progeny. Adult-born neurons (BrdU/NeuN-ir) matured faster in males compared with females. Males had a greater density of neural stem cells (Sox2-ir) in the dorsal, but not in the ventral, DG and had higher levels of cell proliferation (Ki67-ir) than non-proestrous females. However, males showed a greater reduction in neurogenesis between 1 week and 2 weeks after mitosis, whereas females showed similar levels of neurogenesis throughout the weeks. The faster maturation and greater attrition of new neurons in males compared with females suggests greater potential for neurogenesis to respond to external stimuli in males and emphasizes the importance of studying sex on adult hippocampal neurogenesis.
\end{abstract}

Key words: BrdU; dentate gyrus; doublecortin; KI67; cell proliferation; cell survival; Sox2

\section{Significance Statement}

Previously studies examining the characteristics of adult-born neurons in the dentate gyrus (DG) have used almost exclusively male subjects. Researchers have assumed the two sexes have a similar maturation and attrition of new neurons in the DG of adults. However, this study highlights notable sex differences in the attrition, maturation rate, and potential of neurogenesis in the adult hippocampus that has significant implications for the field of neuroplasticity. These findings are important in understanding the relevance of sex differences in the regulation of neurogenesis in the hippocampus in response to stimuli or experience and may have consequences for our understanding of diseases that involve neurodegeneration of the hippocampus, particularly those that involve sex differences, such as Alzheimer's disease and depression.

\section{Introduction}

Adult neurogenesis in the dentate gyrus (DG) has been observed in all mammalian species studied including primates (Kuhn et al., 1996; Gould et al., 1999; Kornack and Rakic, 1999; Knoth et al., 2010; Briley et al., 2016; Boldrini

Received November 11, 2019; accepted June 18, 2020; First published June 25, 2020.

The authors declare no competing financial interests. et al., 2018; Moreno-Jiménez et al., 2019). Despite two papers indicating a lack of neurogenesis in humans (Dennis et al., 2016; Sorrells et al., 2018), recent studies have definitively shown adult neurogenesis exists in humans and is modulated by disease, age, and perhaps sex

Author contributions: S.Y. and L.A.M.G. designed research; S.Y., J.E.J.S., D.T., S.W., and Y.W. performed research; S.Y., J.E.J.S., Y.W., and L.A.M.G. analyzed data; S.Y. and L.A.M.G. wrote the paper. 
in response to antidepressants (Epp et al., 2013; Cipriani et al., 2018; Sorrells et al., 2018; Moreno-jiménez et al., 2019; Tobin et al., 2019). Adult hippocampal neurogenesis arises from the radial glia-like neural stem cells (RGLs; type1; Fig. 1) in the subgranular zone of the DG, which express stage-specific proteins such as Sox2. Sox2 plays a critical role maintaining pluripotency of RGLs (Steiner et al., 2006; Bonaguidi et al., 2011; Encinas et al., 2011; Amador-Arjona et al., 2015; Micheli et al., 2018). The RGLs undergo asymmetrical cell division and generate one RGL and either an astroglia or a transiently amplifying intermediate neural progenitor cell (IPC; type2). The IPCs can undergo multiple symmetrical or asymmetrical cell divisions but generally daughter cells differentiate into neurons (Cameron et al., 1993; Kempermann et al., 2003; Steiner et al., 2006; Bonaguidi et al., 2011; Encinas et al., 2011). Previous studies show that adult-born cells in the DG divide multiple times, increasing the number of daughter cells which peaks 1 week (1w) after initial mitosis in male rats (Cameron et al., 1993) and perhaps earlier in mice (Amador-Arjona et al., 2015). Adult-born cells in the DG start to die off and show a rapid decrease in the number of new cells between $1 w$ and $3 w$ after the initial cell division in male rodents (Cameron et al., 1993; Snyder et al., 2009; Encinas et al., 2011). A subset of IPCs (type2b), neuroblasts (type3), and immature neurons transiently express a microtubule-associated protein, doublecortin (DCX) for up to $3 w$, and new neurons start to express a neuronal nuclear protein, NeuN, approximately $1 \mathrm{w}$ after mitosis in rats (Brown et al., 2003; Snyder et al., 2009) or $2 \mathrm{w}$ after mitosis in mice (Snyder et al., 2009). Surviving new neurons integrate into the existing neural circuitry, and play an important role in pattern separation and stress resilience (Clelland et al., 2009; Snyder et al., 2011; Hill et al., 2015; França et al., 2017). However, whereas there are species differences in the maturation rate of adult born neurons (Snyder et al., 2009), as of yet, no studies to our knowledge have explored sex differences in the maturation rate of adult born neurons.

It is important to acknowledge that most of our information about the trajectory and timeline of maturation of new neurons comes from data in male rodents (Cameron et al., 1993; Snyder et al., 2009), with one study in female rodents (Brown et al., 2003). Previous studies demonstrate notable sex differences in the regulation of adult neurogenesis in response to stress, estrogens, androgens, or cognitive training in the DG (Falconer and Galea, 2003; Barker and Galea, 2008; Chow et al., 2013; Hillerer et al.,

This work was supported by the Natural Sciences and Engineering Research Council (NSERC) Discovery Grant RGPIN-2018-04301 (to L.A.M.G.) and by a Izaak Walton Killam Memorial Pre-Doctoral Fellowship (S.Y.).

Acknowledgements: We thank Tanvi Puri, Yanhua Wen, and Stephanie Lieblich for the exceptional technical assistance with this work.

Correspondence should be addressed to Liisa A. M. Galea at liisa.galea@ ubc.ca.

https://doi.org/10.1523/ENEURO.0468-19.2020

Copyright (C) 2020 Yagi et al.

This is an open-access article distributed under the terms of the Creative Commons Attribution 4.0 International license, which permits unrestricted use, distribution and reproduction in any medium provided that the original work is properly attributed.
2013; Yagi et al., 2016; Duarte-Guterman et al., 2019). For instance, acute stress suppresses adult neurogenesis in male rats, but not in female rats (Falconer and Galea, 2003; Hillerer et al., 2013). Furthermore, spatial navigation tasks or spatial pattern separation tasks enhance adult neurogenesis in male rats but not in female rats (Chow et al., 2013; Yagi et al., 2016). The enhancing effect of cognitive training on adult neurogenesis in male rats has a critical period, in which cognitive training must occur 6-10 d after cell birth (Epp et al., 2011), which is curiously the same time that $17 \beta$-estradiol also increases neurogenesis in the male meadow vole (Ormerod et al., 2004). The sex differences in the ability of cognitive training to enhance neurogenesis in males but not females suggests one of three scenarios: (1) neurogenesis in the hippocampus is not important for cognitive training in females; (2) the neural activity in the hippocampus may not be as active in females; or (3) there are sex differences in the maturation rate of neurogenesis. Either of these scenarios would lead to the inability of cognitive training to boost survival of new neurons in females in response to spatial training. However, evidence suggests neither of the first two scenarios are correct. Adult DG neurogenesis is associated with better performance in females (Chow et al., 2013; Yagi et al., 2016) and females show increased zif268 expression in the CA3 after training compared with males (Yagi et al., 2016, 2017). Collectively, these findings suggest sex differences following cognitive training may be due to differences in the maturation rate and perhaps trajectory of adult-born neurons in the DG.

Therefore, the present study aimed to elucidate whether there were sex differences in the maturation and attrition of the new neurons as well as the number of neural stem cells in the dorsal versus ventral DG. A single injection of bromodeoxyuridine (BrdU) was used for birth-dating of adult-born new cells in male and female rats, and brains were immunohistochemically stained for BrdU and endogenous cell-stage-specific protein makers such as Sox2, Ki67, DCX, and NeuN. Given the work above, we expected sex differences in the maturation rate of new neurons with males showing a faster maturation rate than females.

\section{Materials and Methods}

\section{Animals}

Forty-four age-matched (two-month-old) Sprague Dawley rats were bred at the University of British Columbia and used in this study ( $n=22$ per sex). All subjects were same-sex pair-housed in opaque polyurethane bins $(48 \times 27 \times 20 \mathrm{~cm})$ with paper towels, polyvinylchloride tube, cedar bedding, under a 12/12 h light/dark cycle with 7 A.M. lights-on. Food and water were provided ad libitum. Females weighed $240-280 \mathrm{~g}$ and males weighed 315-355 g. All animals were handled every day for $2 \mathrm{~min}$ for $1 \mathrm{w}$ before the beginning of the experiment. All experiments were conducted in accordance with Canadian Council for Animal Care guidelines and were approved by the animal care committee at the University of British Columbia. All efforts were made to reduce the number of animals used and their suffering during all procedures. 


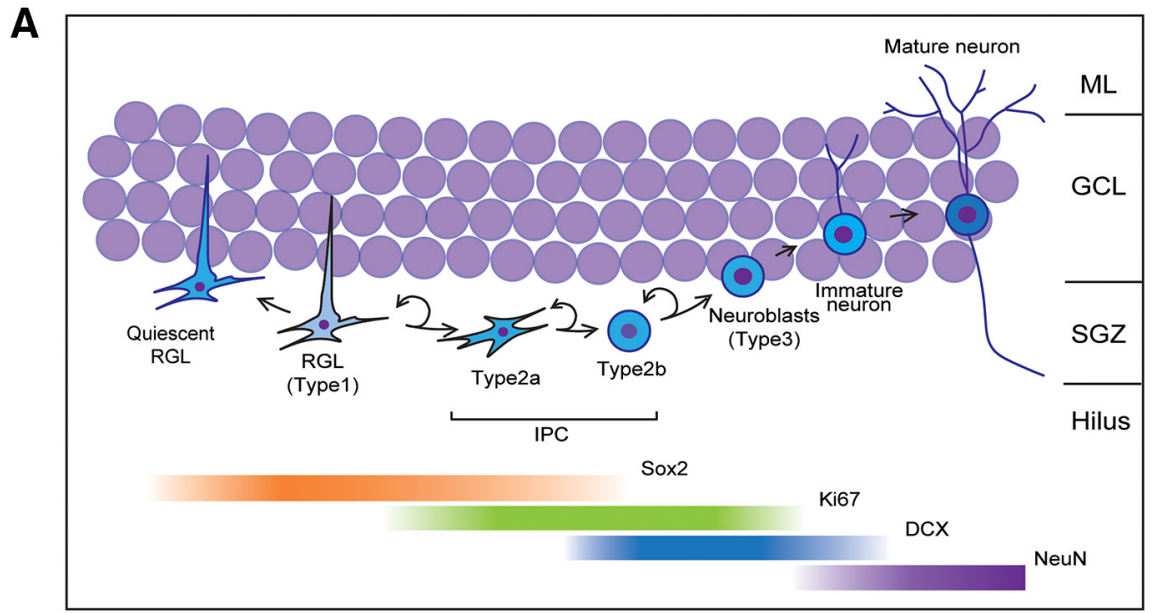

B
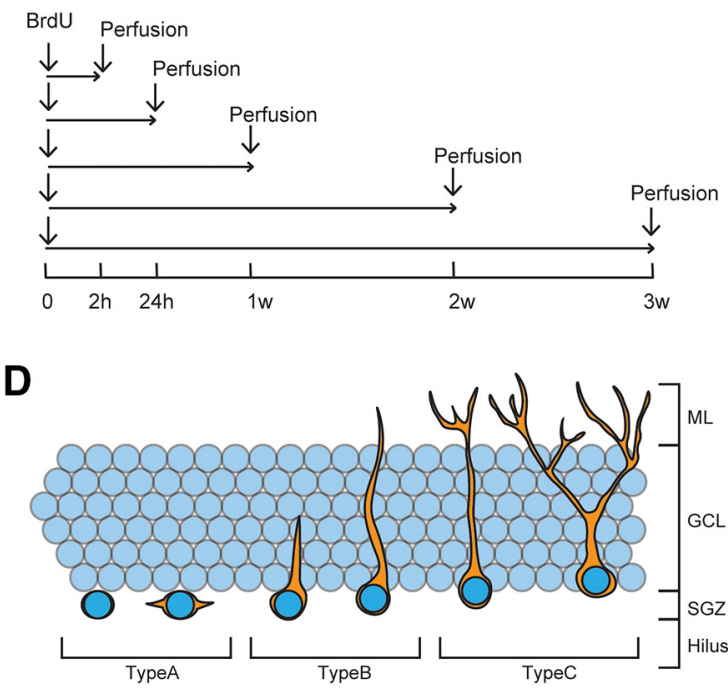

C

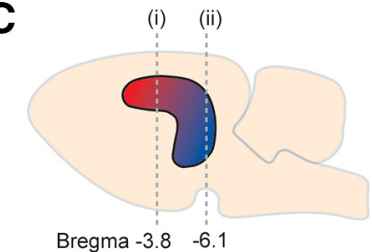

(i)

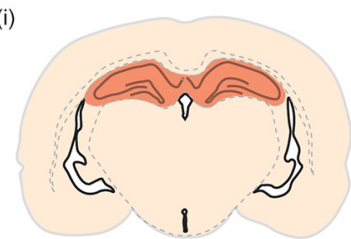

(ii)

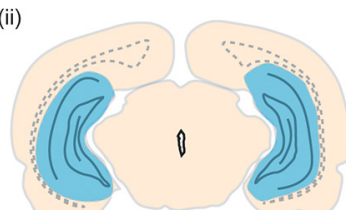

Figure 1. $\boldsymbol{A}$, Schematic illustrations for the timeline of neural stem cell lineage with expression of stage-specific proteins (Steiner et al., 2006; Bonaguidi et al., 2011; Encinas et al., 2011; Amador-Arjona et al., 2015; Micheli et al., 2018). B-D, Schematic illustrations for the experimental design. $\boldsymbol{B}$, The experimental timeline, all animals were age-matched and received BrdU injection at 10 weeks. Examples of the dorsal (section $\boldsymbol{i}$ : red; bregma $-3.8 \mathrm{~mm}$ ) and ventral (section ii: blue; bregma $-6.8 \mathrm{~mm}$ ) hippocampus (numbers represent mm from the bregma; $(\boldsymbol{C})$ and morphologic phenotypes of DCX-ir cells $(\boldsymbol{D})$. h- hours, w- weeks, BrdU- bromodeoxyuridine, DCX- doublecortin, GCL- granule cell layer, IPC- intermediate proliferating cell, ML- molecular layer, RGL- radial glial cell, SGZ- subgranular zone.

\section{Experimental design}

One intraperitoneal (i.p.) injection of BrdU $(200 \mathrm{mg} / \mathrm{kg})$ was given to all rats between 11 A.M. and 12 P.M. Rats were perfused either $2 \mathrm{~h}, 24 \mathrm{~h}, 1 \mathrm{w}, 2 \mathrm{w}$, or $3 \mathrm{w}$ after the BrdU injection, but otherwise were left undisturbed except for weekly cage changes (see Fig. 1B). On the day of perfusion, rats were administered an overdose of sodium pentobarbital $(500 \mathrm{mg} / \mathrm{kg}$, i.p.). Blood samples were collected from the chest cavity, and rats were perfused transcardially with $60 \mathrm{ml}$ of $0.9 \%$ saline followed by 120 $\mathrm{ml}$ of $4 \%$ paraformaldehyde (Sigma-Aldrich). Brains were extracted and postfixed in $4 \%$ paraformaldehyde overnight, then transferred to $30 \%$ sucrose (Fisher Scientific) solution for cryoprotection and remained in the solution until sectioning. Brains were sliced into $30-\mu \mathrm{m}$ coronal sections using a Leica SM2000R microtome (Richmond Hill). Sections were collected in series of ten throughout the entire rostral-caudal extent of the hippocampus and stored in anti-freeze solution consisting of ethylene glycol, glycerol, and $0.1 \mathrm{~m} \mathrm{PBS}$ at $-20^{\circ} \mathrm{C}$ until immunostaining. Complete series of sections were immunohistochemically stained for BrdU/DCX and BrdU/NeuN to examine sex differences in the maturation timeline of new neurons, for Sox2 to examine the number of neural stem cells, and for Ki67 to examine actively dividing progenitor cells. In addition, the brain sections were double-stained for BrdU/ Sox2 to examine changes of Sox2 expression over the $3 \mathrm{w}$ after BrdU injection.

\section{Radioimmunoassay (RIA) for $17 \beta$-estradiol and testosterone}

Previous studies reported that $17 \beta$-estradiol increases cell proliferation in females but not males (Tanapat et al., 
Table 1: Mean ( \pm SEM), minimum and maximum concentration of serum testosterone in males $(\mathrm{ng} / \mathrm{ml})$ and estradiol in females $(\mathrm{pg} / \mathrm{ml})$

\begin{tabular}{llll}
\hline & Min & Max & Mean \pm SEM \\
\hline Male (testosterone) & 0.37 & 4.46 & $1.067 \pm 0.43$ \\
Female (estradiol) & 10.99 & 21.08 & $14.41 \pm 1.30$
\end{tabular}

$n=13$ per group

1999; Barker and Galea, 2008). Androgens increase survival of new neurons in males but not in females, but do not influence cell proliferation in either sex (Spritzer and Galea, 2007; Duarte-Guterman et al., 2019). Thus, we examined serum levels of $17 \beta$-estradiol and testosterone in females and males of the $1 w, 2 w$, and $3 w$ groups, respectively. Blood samples were stored at $4^{\circ} \mathrm{C}$ overnight and centrifuged at $10 \times g$ for $15 \mathrm{~min}$ to collect serum. Serum $17 \beta$-estradiol levels in female rats and serum testosterone levels in male rats were assayed using commercially available RIA kits from Beckman Coulter or MP Biomedicals, respectively. The sensitivity of the RIA kits was $0.75 \mathrm{ng} / \mathrm{ml}$ for $17 \beta$-estradiol and $0.03 \mathrm{ng} / \mathrm{ml}$ for testosterone. The intraassay and interassay coefficients of variation were $<8.9 \%$ and $<12.2 \%$, respectively, for $17 \beta$-estradiol and $<8.2 \%$ and $<13.2 \%$ for testosterone. For females with $50 \mathrm{pg} / \mathrm{ml}$ or higher serum estradiol levels were considered to be in proestrus (Cameron et al., 2008). Based on estradiol levels, none of the females in the $1 w, 2 w$, and $3 w$ groups were in proestrus at the time of perfusion (see Table 1).

\section{Estrous cycle stage determination}

As the estrous cycle phase can influence cell proliferation (Tanapat et al., 1999; Rummel et al., 2010), estrous cycle stages of the 2 and $24 \mathrm{~h}$ groups were determined with vaginal lavage samples. Vaginal cells suspended in water were obtained using a glass pipette, transferred onto a microscope slide and stained with cresyl violet (Sigma-Aldrich). Proestrus was determined when $70 \%$ of the cells were nucleated epithelial cells. Two females (one each in the 2 and $24 \mathrm{~h}$ groups) were in proestrus at the time of perfusion.

\section{Immunohistochemistry}

BrdU/NeuN, BrdU/DCX, or BrdU/Sox2 double-staining

The exogenous DNA synthesis marker, BrdU is incorporated into DNA during the synthesis phase of the cell cycle (Kee et al., 2002; Miller et al., 2018). BrdU is a thymidine analog which is active for $2 \mathrm{~h}$ after injection in rats (Cameron and Mckay, 2001). Briefly our protocol was as follows: sections were prewashed three times with $0.1 \mathrm{M}$ TBS and left overnight at $4^{\circ} \mathrm{C}$. Sections were then incubated in a primary antibody solution containing 1:250 mouse anti-NeuN (Millipore), 1:200 goat anti-DCX (Santa Cruz Biotechnology) or 1:500 mouse anti-Sox2 (Santa Cruz Biotechnology), 0.3\% Triton X-100, and 3\% normal donkey serum (NDS; Vector Laboratories) in $0.1 \mathrm{~m}$ TBS for $24 \mathrm{~h}$ at $4^{\circ} \mathrm{C}$. Next, sections were incubated in a secondary antibody solution containing 1:250 donkey anti-mouse
Alexa Fluor 488 (Invitrogen) or donkey anti-goat Alexa Fluor 488 (Invitrogen) in $0.1 \mathrm{M} \mathrm{TBS}$, for $18 \mathrm{~h}$ at $4^{\circ} \mathrm{C}$. After being rinsed three times with TBS, sections were washed with $4 \%$ paraformaldehyde for $10 \mathrm{~min}$, and rinsed twice in $0.9 \% \mathrm{NaCl}$ for $10 \mathrm{~min}$, followed by incubation in $2 \mathrm{~N} \mathrm{HCl}$ (Fisher Scientific) for $30 \mathrm{~min}$ at $37^{\circ} \mathrm{C}$. Sections were then rinsed three times in TBS for $10 \mathrm{~min}$ each and incubated in a BrdU primary antibody solution consisting of 1:500 rat anti-BrdU (AbD Serotec), 3\% NDS, and 0.3\% Triton X-100 in $0.1 \mathrm{M}$ TBS for $24 \mathrm{~h}$ at $4^{\circ} \mathrm{C}$. A further incubation of sections commenced in a secondary antibody solution containing 1:500 donkey anti-rat Alexa Fluor 594 (Invitrogen) in $0.1 \mathrm{M}$ TBS for $24 \mathrm{~h}$ at $4^{\circ} \mathrm{C}$. Following three final rinses with TBS, the sections were mounted onto microscope slides and cover-slipped with PVA DABCO.

\section{Ki67 or Sox2 immunofluorescent staining}

$\mathrm{Ki} 67$ is expressed in actively dividing cells (all stages of the cell cycle except $\mathrm{G}_{0}$ ) and therefore is expressed at higher levels than BrdU $24 \mathrm{~h}$ after injection of BrdU (Kee et al., 2002). Randomly selected brain sections from the same animal were also immunohistochemically stained with anti-Ki67 or anti-Sox2 ( $n=8$ per sex). Brain sections were prewashed with $0.1 \mathrm{~m}$ PBS and left to sit overnight at $4^{\circ} \mathrm{C}$. The next day, sections were incubated in $10 \mathrm{~mm}$ sodium citrate buffer for $45 \mathrm{~min}$ at $90^{\circ} \mathrm{C}$ to retrieve antigens of Ki67 and blocked with 3\% NDS and 0.3\% Triton X-100 in $0.1 \mathrm{M}$ PBS, followed by incubation in primary antibody solution made with 1:1000 mouse anti-Sox2 (Santa Cruz Biotechnology) or 1:250 mouse anti-Ki67 (Leica Biosystems), 1\% NDS, and 0.3\% Triton X-100 in $0.1 \mathrm{M}$ PBS for $24 \mathrm{~h}$ at $4^{\circ} \mathrm{C}$. Then the sections were incubated in secondary antibody solution, consisting of 1:500 donkey anti-mouse Alexa Fluor 488 for Sox2 (Invitrogen) and 1:500 donkey anti-mouse Alexa Fluor 594 for Ki67 (Invitrogen), 1\% NDS, and $0.3 \%$ Triton X-100 in $0.1 \mathrm{M}$ PBS, for $18 \mathrm{~h}$ at $4{ }^{\circ} \mathrm{C}$. After three rinses with PBS, sections were incubated in 1:5000 DAPI in PBS for 3 min and mounted onto slides and cover-slipped with PVA DABCO.

\section{Cell counting}

All counting was conducted by an experimenter blind to the group assignment of each animal using an Olympus epifluorescent microscope and confocal microscope. Location of immunoreactive cells was examined in the dorsal or ventral DG using the criterion defined by Banasr et al. (2006) with sections 7.20-4.48 mm from the interaural line (bregma -1.80 to $-4.52 \mathrm{~mm}$ ) defined as dorsal and sections $4.48-2.20 \mathrm{~mm}$ from the interaural line (breg$\mathrm{ma}-4.52$ to $-6.80 \mathrm{~mm}$ ) as ventral (Banasr et al., 2006; see Fig. 1C). Cells were counted separately in each region because the different regions are associated with different functions (for review, see Fanselow and Dong, 2010) and possibly different maturation timelines (Snyder et al., 2012). The dorsal hippocampus is associated with spatial learning and memory, whereas the ventral hippocampus is associated with stress and anxiety (Moser et al., 1993; Kjelstrup et al., 2002). 


\section{BrdU and Ki67}

Ki67-ir and BrdU-ir cells were counted under a $100 \times$ oil immersion objective lens. Every 10th section of the granule cell layer (GCL) that includes the subgranular zone on one half of each brain were counted. An estimate of the total number of cells was calculated by multiplying the aggregate by 10 (Snyder et al., 2005; Ngwenya et al., 2015; Workman et al., 2015). Density of BrdU-ir or Ki67-ir cells was calculated by dividing the total estimate of immunoreactive cells in the GCL by volume of the corresponding region. The volume of the DG was calculated using Cavalieri's principle (Gundersen and Jensen, 1987) by multiplying the summed areas of the DG by thickness of the section $(300 \mu \mathrm{m})$. Area measurements for the DG were obtained using digitized images on the software ImageJ (NIH).

\section{Percentage of BrdU/NeuN, BrdU/DCX, and BrdU/Sox2 co-expression}

The percentages of BrdU/NeuN and BrdU/DCX-ir cells were obtained by randomly selecting 50 BrdU-labeled cells and calculating the percentage of cells that co-expressed DCX, NeuN, or Sox2 (method used by Banasr et al., 2006). The percentage of BrdU/DCX-ir cells was also categorized into the three morphology types using the criteria used by Plümpe et al. (2006). Briefly, stages were defined as type-A proliferative: neurons with no or short plump processes; type-B intermediate: neurons possess medium-length processes or apical dendrites that reach the molecular layer; and type-C postmitotic: neurons possess apical dendrites with at least one branching into the molecular layer (see Fig. 1D). The density of BrdU-ir cells was multiplied by the percentage of BrdU-ir cells that expressed DCX or Sox2.

\section{Sox2}

Photomicrographs of the DG were obtained with a $20 \times$ objective lens of an Olympus confocal microscope (three images from three sections each from the dorsal and ventral DG). Immunoreactive cells were counted automatically using a code developed by JEJS from the digitized images using MATLAB (MathWorks). Briefly, the program first introduces a graphical interface with the chosen image and the user can freehand trace the region of interest (ROI). The program provides the total area of the ROI. The image is then converted to grayscale, assigning each pixel with an intensity value [0 (black) to 255 (white)]. The Sox2-ir cells are brighter in the image and thus have higher corresponding pixel values. The background of the image is obtained by MATLAB's imopen function to morphologically open and select out disk structural elements with a radius of 10 pixels (roughly the average size of the cells in the original image). This serves to create a new image in which all the cells in the picture are removed. A new image is created by removing the background image from the grayscale image and then contrasting the result to extract the bright cells from the grayscale image. To account for image artifacts and ensure accurate counting, the contrasted image then has the original background image removed multiple times. For our Sox2 images, we found that by subtracting the background three to five times would provide accurate counts. Finally, the image is then binarized (pixels given a value of 0 or 1 ) and size restrictions are placed removing any remaining artifacts that are too large or too small to be a cell. The final image is read, cells are counted, the area of the ROI (total pixels in freehand trace), area of the cells (total pixels counted as a cell) are used. Interrater reliability scores were calculated comparing three human counters, blinded to program results were high $(r=0.93, p=0.024)$ and the program compared with itself (4-5 $\times$ background removed $r=0.98$, $p=0.003)$. The code is available by contacting the corresponding author.

\section{Statistical analyses}

All analyses were conducted using STATISTICA (StatSoft). The density of BrdU-ir cells, BrdU-ir/DCX-ir, or the percentage of BrdU-ir cells that express Sox2 or DCX were each analyzed using repeated-measures ANOVA, with maturation time $(2 \mathrm{~h}, 24 \mathrm{~h}, 1 \mathrm{w}, 2 \mathrm{w}, 3 \mathrm{w})$ and sex (male, female) as between-subject variables and with hippocampal region (dorsal, ventral) as the within-subject variable. The percentage of BrdU-ir cells that express NeuN was analyzed using a repeated-measures ANOVA, with maturation time (1w, 2w, 3w) and sex (male, female) as between-subject variables and with hippocampal region (dorsal, ventral) as the within-subject variable. Repeated-measures ANOVAs were used to each analyze the density of Ki67-ir and Sox2-ir cells with sex as between subject factor and with hippocampal region as the within-subject factor. Pearson product-moment correlations were calculated to examine the relationship between dependent variables of interest. Furthermore, the percentage of BrdU/DCX-ir cells expressing type-C morphology was analyzed using repeated-measures ANOVA with sex as between-subject variables and with maturation time and hippocampal region as within-subject variables. Post hoc tests used the Neuman-Keuls procedure. A priori comparisons were subjected to Bonferroni corrections. Significance was set to $\alpha=0.05$ and effect sizes are given with Cohen's $d$ or partial $\eta^{2}$.

\section{Results}

\section{Males had larger dorsal DG volumes compared with females}

As expected, males had significantly greater volume of dorsal DG compared with females and as such cell density was used for direct comparison between the sexes for all analyses ( $p=0.012$; region by sex interaction: $F_{(1,22)}=4.61$, $p=0.043$, Cohen's $d=1.26$; see Table 2). In addition, the ventral DG was larger than the dorsal DG, as expected (main effect of region: $F_{(1,22)}=36.19, p<0.0001$ ).

\section{Males had greater levels of cell proliferation (Ki67) compared with females}

To examine potential sex differences in cell proliferation, we used Ki67, which labels all cells undergoing mitosis. Males had a greater density of Ki67-ir cells compared with females (main effect of sex: $F_{(1,15)}=13.90, p=0.002$, Cohen's $d=1.80$; see Fig. $2 B$ ). There was also a trend of main effect of region $\left(F_{(1,15)}=3.44, p=0.083\right.$, partial $\eta^{2}=$ 
Table 2: Mean ( \pm SEM) volume of the dorsal and ventral DG in male and female rats $\left(\mathrm{mm}^{3}\right)$

\begin{tabular}{lll}
\hline & Dorsal & Ventral \\
\hline Male & $0.905 \pm 0.056$ & $1.334 \pm 0.083$ \\
Female & $0.688 \pm 0.043$ & $1.593 \pm 0.195$ \\
\hline
\end{tabular}

Females had a smaller dorsal DG volume, $n=42$ (20 males and 22 females).

$0.187)$, but no significant interaction $(p=0.11)$. Because previous studies have observed the rats in proestrus have higher levels of cell proliferation (Tanapat et al., 1999; Rummel et al., 2010), we also examined the relationship between the density of Ki67-ir cells and the levels of $17 \beta-$ estradiol in females, or testosterone in males, but no significant relationships were observed (all $p s>0.268$ ).

\section{Males, but not females, show greater attrition of BrdU-ir cells from $1 w$ to $2 w$ after mitosis}

To determine whether there were sex differences in the trajectory of new neurons across time, we examined the density of BrdU-ir cells at various time points after BrdU injection ( $2 \mathrm{~h}, 24 \mathrm{~h}, 1 \mathrm{w}, 2 \mathrm{w}$, and $3 \mathrm{w})$. Using the same timeline with ${ }^{3} \mathrm{H}$-thymidine, males show an increase ${ }^{3} \mathrm{H}$-thymidine-labeled cells after $24 \mathrm{~h}$ and a large attrition rate of ${ }^{3} \mathrm{H}$-thymidine-labeled from $1 \mathrm{w}$ to $3 \mathrm{w}$ after injection (Cameron et al., 1993). Consistent with past research (Cameron et al., 1993), males had a greater density of ono-week-old BrdU-ir cells compared with 2 h, 24 h, 2 w, and $3 w$ after BrdU injection ( $p s<0.001$; interaction effect of sex by time; $F_{(4,31)}=2.95, p=0.035$, partial $\eta^{2}=0.276$; see Fig. 3). However, females did not show appreciable differences in the density of BrdU-ir cells across any time points (all ps>0.147) except between 2 and $24 \mathrm{~h}$ $(p=0.156)$. Furthermore, males had a greater density of BrdU-ir cells than females at the $1 \mathrm{w}$ time point $(p=0.0003$, Cohen's $d=2.26)$ but not at any other time point (all $p s>0.308$ ). Given our findings with Ki67, we also examined sex differences at the 2- and 24-h time points and saw males had more BrdU-ir cells in the dorsal region only at 2 h (a priori: $p=0.009$, Cohen's $d=2.64$ ) which failed to reach significance at $24 \mathrm{~h}(p=0.15) \mathrm{com}-$ pared with females. There were main effects of sex $\left(F_{(1,31)}=17.57, p<0.002\right.$, Cohen's $\left.d=0.746\right)$, time $\left(F_{(4,31)}=11.78, p<0.0001\right.$, partial $\left.\eta^{2}=0.603\right)$, and region $\left(F_{(1,31)}=4.43, p=0.044\right.$, Cohen's $\left.d=0.254\right)$, and an interaction effect of region by time $\left(F_{(4,31)}=12.21\right.$, $p<0.0001$, partial $\eta^{2}=0.639$ ) was noted but no other significant interactions ( $p s>0.125)$.

Complementing the attrition rate in BrdU-ir cells across weeks in males, we found that males had a greater density of BrdU/DCX-ir cells than females only at the $1 \mathrm{w}$ time point ( $p=0.00,036$, Cohen's $d=2.61$ ) but not at any other time point (all $p s>0.130$; interaction effect of sex by time: $F_{(4,29)}=4.04, p=0.0101$, partial $\eta^{2}=0.358$; see Fig. $3 B$ ). Given our findings with Ki67, we also examined the 2- and 24-h time point and found that males had a greater density of BrdU/DCX-ir cells compared with females in the dorsal DG at $2 \mathrm{~h}(p=0.005$, Cohen's $d=3.18)$. There were also main effects of sex $\left(F_{(1,29)}=11.71, p=0.0047\right.$, Cohen's $d=0.320)$, time $\left(F_{(4,29)}=29.31\right.$, $p<0.0001$, partial $\left.\eta^{2}=0.802\right)$, and region $\left(F_{(1,29)}=8.66, p=0.0063\right.$, partial

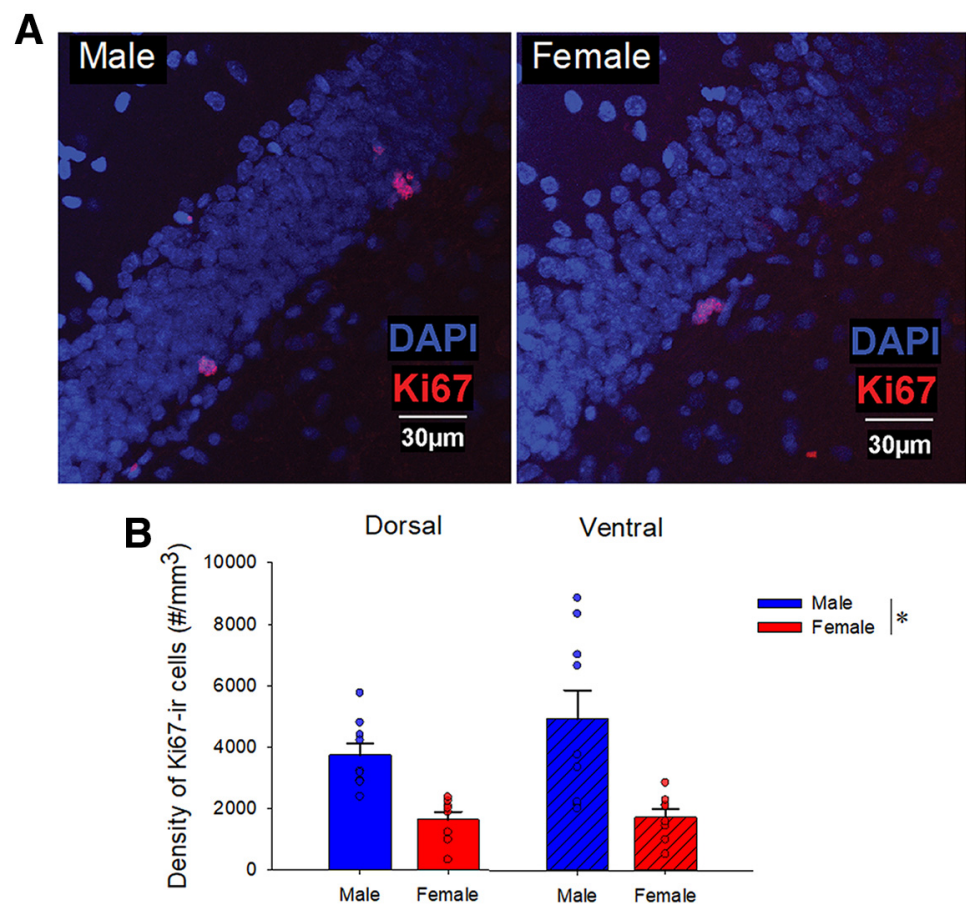

Figure 2. Sex differences in proliferating cells (Ki67-ir) in the DG. (A) Photomicrographs of Ki67 (red) with DAPI (blue) taken with $40 \times$ objective from a male (left) and female (right) young adult rat (11 weeks old) in the dorsal DG. (B) Mean ( \pm SEM) density of Ki67ir cells: males had a greater density of Ki67-ir cells compared with females; * indicates a significant difference $(p<0.05)$. ir, immunoreactive. All animals were age-matched. SEM-standard error of the mean, DAPI- 4',6-diamidino-2-phenylindole, DG-dentate gyrus. 

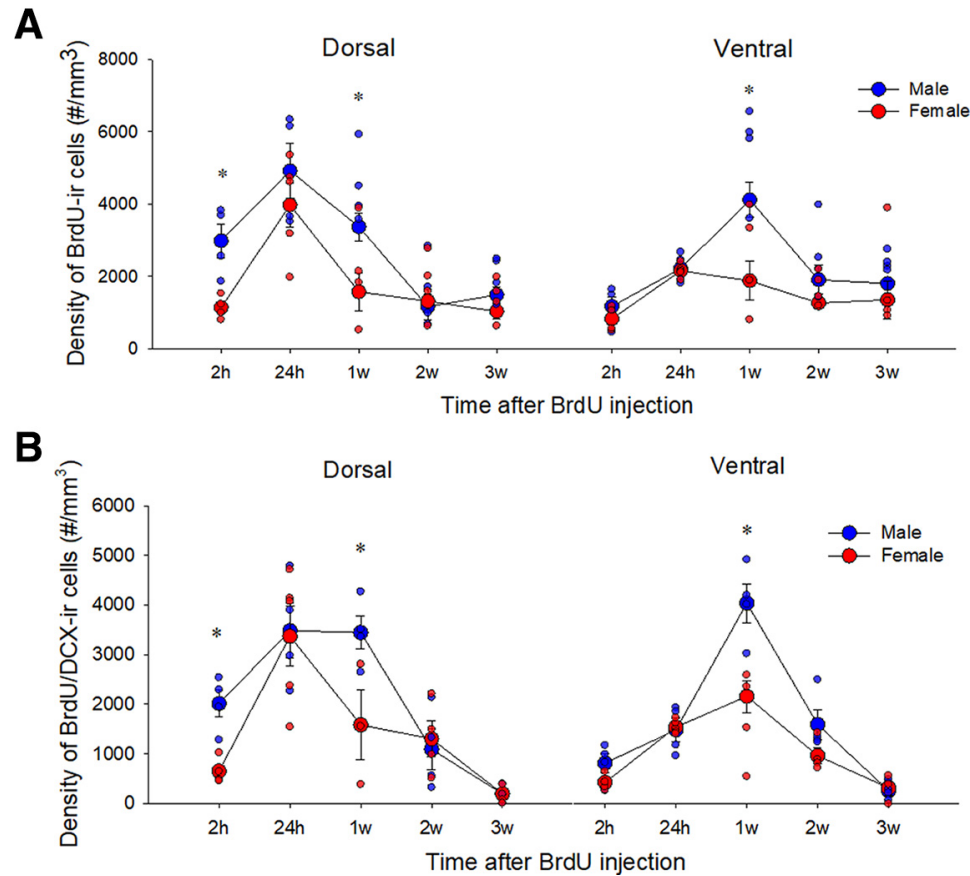

Figure 3. Sex differences in the trajectory of adult-born BrdU-ir cells. $\boldsymbol{A}$, Mean ( \pm SEM) density of BrdU-ir cells. Male adult rats had a greater density of BrdU-ir cells at $2 \mathrm{~h}$ and $1 \mathrm{w}$ compared with female adult rats and showed a greater reduction in density between $1 \mathrm{w}$ and $2 \mathrm{w}$ after BrdU injection. B, Mean ( \pm SEM) density of BrdU/DCX-ir cells. Males had a greater density of BrdU-ir cells that express DCX cells at $2 \mathrm{~h}$ and $1 \mathrm{w} ; *$ indicates a significant sex difference $(p<0.05)$. All animals were age-matched and received BrdU injection at 10 weeks. h-hours, w-weeks, BrdU- bromodeoxyuridine, DCX-doublecortin, SEM-standard error of the mean, ir-immunoreactive.

$\eta^{2}=0.230$ ), and an interaction effect of region by time $\left(F_{(4,29)}=12.86, p<0.0001\right)$, partial $\left.\eta^{2}=0.639\right)$ but no other significant interactions were noted ( $p s>0.269$ ).

\section{Male adult-born neurons mature faster compared with female adult-born neurons}

We then examined whether there are sex differences in maturation rate of adult-born neurons by examining the percentage of BrdU-ir cells expressing maturation stage specific neuronal markers, immature neurons (DCX) and mature neurons (NeuN) across the 3 weeks. Males, compared with females, had a greater percentage of BrdU-ir cells that expressed NeuN 2w $(p=0.003$, Cohen's $d$ $=2.14)$ but not $1 \mathrm{w}(p=0.99)$ or $3 \mathrm{w}(p=0.54)$ after BrdU injection (interaction effect of sex by time; $F_{(2,17)}=3.52$, $p=0.05$, partial $\eta^{2}=0.293$; see Fig. $4 B$ ). There were also main effects of sex: $\left(F_{(1,17)}=7.14, p=0.016\right.$, partial $\eta^{2}=$ $0.296)$ and time $\left(F_{(2,16)}=41.92, p<0.00,001\right.$, partial $\eta^{2}=$ $0.834)$ but no other significant main or interaction effects (all ps $>0.24$ ). The percentage of BrdU-ir cells that expressed NeuN by 3 weeks after BrdU injection in both males and females was $\sim 90 \%$ and did not significantly differ between the sexes $(p=0.583)$.

As expected, in both sexes across both regions, the percentage of BrdU-ir cells that also express DCX decreased significantly as time progressed with the least co-expression at $3 \mathrm{w}$ compared with all other time points (all ps $<0.002$ ). Furthermore, the $2 \mathrm{~h}$ time point had lower co-expression than all other earlier time points (all $p s$ $<0.024)$ except $2 \mathrm{w}(p=0.34)$ and $3 \mathrm{w}$ (main effect of time: $F_{(4,30)}=63.69, p<0.0001$; partial $\eta^{2}=0.895$; see Fig. $5 B$ ).
Females had greater percentage of BrdU-ir cells that coexpressed DCX in $24 \mathrm{~h}$ group compared with $2 \mathrm{~h}$ group (a priori: $p=0.0003$, Cohen's $d=6.68$; see Fig. $5 B$ ), which was not seen in males $[p=0.895$; sex by time interaction $(p=0.086)]$. There were no other significant main or interaction effects on the percentage of BrdU-ir cells that coexpress DCX (ps > 0.12). Given the findings showing that new neurons expressed NeuN faster in males compared with females, we also examined BrdU/DCX-ir cells by maturation stage, which we classified using morphology (Plümpe et al., 2006). Consistent with our BrdU/NeuN findings, males had a greater percentage of BrdU/DCX-ir cells expressing type-C morphology compared with females at $2 \mathrm{w}$ in the dorsal DG (a priori: $p=0.017$, Cohen's $d=1.84$; effect of time: $F_{(2,18)}=5.39, p=0.015$, partial $\eta^{2}=0.37$; see Fig. $\left.6 C\right)$ but not at $1 \mathrm{w}(p=0.95)$ or $3 \mathrm{w}$ $(p=0.84)$ after BrdU injection.

\section{Male rats, compared with female rats, had a greater density of Sox2-ir cells in the dorsal DG; females had greater density of Sox2-ir cells in the ventral compared with dorsal region}

To examine sex differences in neural stem cells, we investigated the expression of Sox2. Sox2 is a transcriptional factor that plays a role in maintaining self-renewal of neural stem cells and is considered a neural stem cell marker. Male rats had a greater density of Sox2-ir cells compared with female rats in the dorsal DG $(p=0.024$, Cohen's $d=1.39$; sex by region; $F_{(1,16)}=6.34 p=0.023$, see Fig. $6 B$ ). Females had a greater density of Sox2-ir cells in the ventral DG compared with the dorsal DG 
A

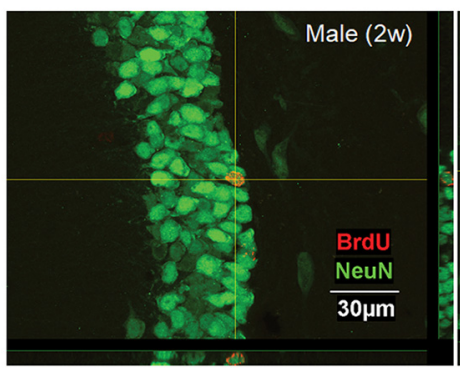

B

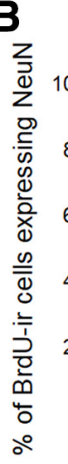

Dorsal

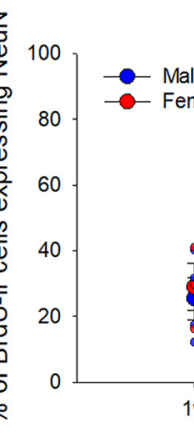

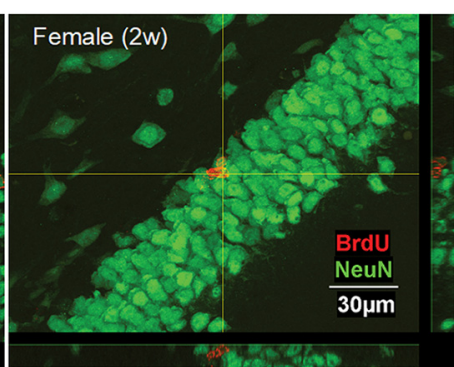

Ventral

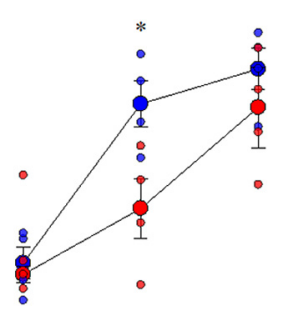

$3 w$

Figure 4. Sex differences in the maturation rate of adult-born neurons in the DG (BrdU/NeuN). $\boldsymbol{A}$, Photomicrographs of BrdU (red)/NeuN (green) taken with $60 \times$ objective lens from a male (left) and female (right) young adult rats in the $2 \mathrm{w}$ group. $\boldsymbol{B}$, Mean ( \pm SEM) percentages of BrdU-ir cells that express NeuN. Male young adult rats had a greater percentage of BrdU-ir cells that express NeuN at $2 \mathrm{w}$ in the dorsal and ventral DG; * indicates a significant sex difference $(p<0.05)$. ir, immunoreactive. All animals were age-matched and received BrdU injection at 10 weeks old. w-weeks, BrdU-bromodoxyuridine, ir- immunoreactive, DG-dentate gyrus SEM-standard error of the mean.

$(p=0.005$, Cohen's $d=1.10)$, whereas this regional difference was not observed in males $(p=0.74)$. There were trends for a main effect of $\operatorname{sex}\left(F_{(1,16)}=3.67, p=0.074\right)$ and region $\left(F_{(1,16)}=4.20, p=0.057\right)$.

\section{Males have a greater density of BrdU/Sox2-ir cells in the dorsal DG at $\mathbf{2} \mathbf{h}$ compared with females}

To understand whether there are differences between sexes in the time course of neural stem cell marker expression after mitosis, we examined the density of BrdU/Sox2-ir cells at $2 \mathrm{~h}, 24 \mathrm{~h}, 1 \mathrm{w}, 2 \mathrm{w}$, and $3 \mathrm{w}$ after BrdU injection. Males had a greater density of BrdU/ Sox2-ir cells compared with females in the dorsal DG at $2 \mathrm{~h}$ but not at any other time point (a priori: $p=0.0019$; see Fig. 7B). In addition, the dorsal DG had a greater density of BrdU/Sox2-ir cells at 2 and $24 \mathrm{~h}$ than the ventral DG compared with all other time points (all ps $<0.0003$; interaction of region by time $F_{(4,31)}=11.66$, $p<0.0001$, partial $\left.\eta^{2}=0.601\right)$. There were also significant main effects of time $\left(F_{(4,31)}=40.46, p<0.0004\right.$, partial $\left.\eta^{2}=0.84\right)$ and region $\left(F_{(1,31)}=20.50, p<0.0001\right.$, partial $\eta^{2}=0.398$ ) but no other main or interaction effects (both $p s>0.109$ ).

\section{The percentage of BrdU/Sox2 co-expressing cells decreased dramatically over time in both sexes}

As expected, the percentage of BrdU-ir cells expressing Sox2 decreased across time, with the highest levels at the 2- and 24-h time points in the dorsal and ventral region (all $p s<0.0002$ ), with the $2 \mathrm{~h}$ time point having higher levels than $24 \mathrm{~h}$ in the dorsal DG only $(p=0.003$; interaction effect of region by time: $F_{(4,31)}=4.25, p=0.007$, partial $\eta^{2}=0.354$; main effect of region: $F_{(1,31)}=5.37$, $p=0.027$, partial $\eta^{2}=0.148$; main effect of time: $F_{(4,31)}=640.85, p<0.001$, partial $\eta^{2}=0.988$; see Fig. $\left.7 C\right)$. There was a trend for an interaction effect of region by sex $\left(F_{(1,31)}=3.77, p=0.061\right.$, partial $\left.\eta^{2}=0.108\right)$. There were no other significant main or interaction effects on the percentage of BrdU-ir cells expressing Sox2 ( $p>0.317)$.

\section{Discussion}

Our findings indicate that adult-born neurons mature faster in males compared with females. We also found notable sex differences in the attrition or survival rate of BrdU-ir cells across time, with males showing reductions across time, and females showing no appreciable reduction in the density of BrdU-ir cells across the three weeks. Furthermore, males had a higher density of dorsal neural stem cells (Sox2) and cell proliferation (Ki67) compared with females. There were notable differences in early expression of DCX in females, but not in males, showing a greater percentage of BrdU-ir cells expressing DCX at 24 hours compared with 2 hours. Intriguingly, the density of BrdU-ir cells two weeks after production was comparable between males and females. Although a tremendous amount of research has unveiled the characteristics of neurogenesis in the adult hippocampus, these findings underscore that we cannot assume that the same characteristics will be similar in females as they are in males. 
A

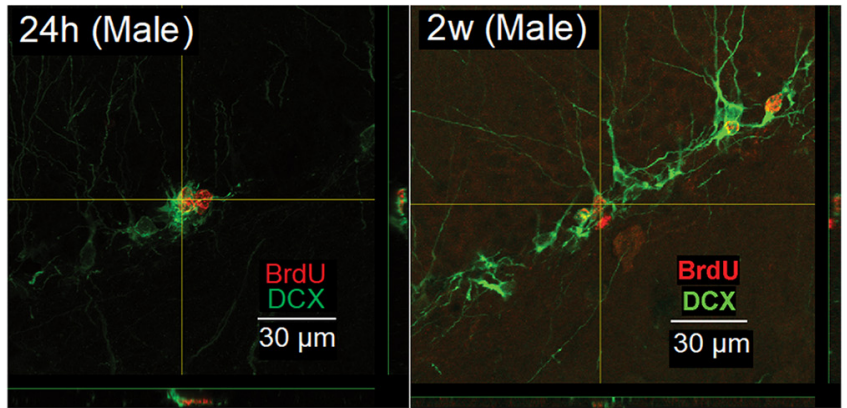

B

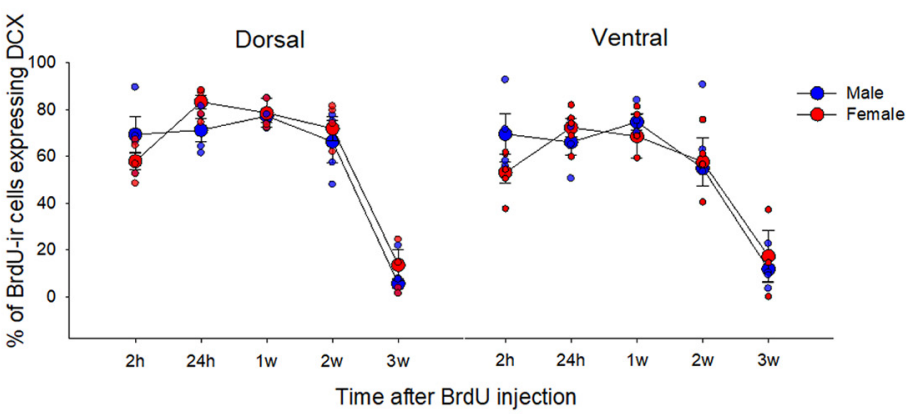

C

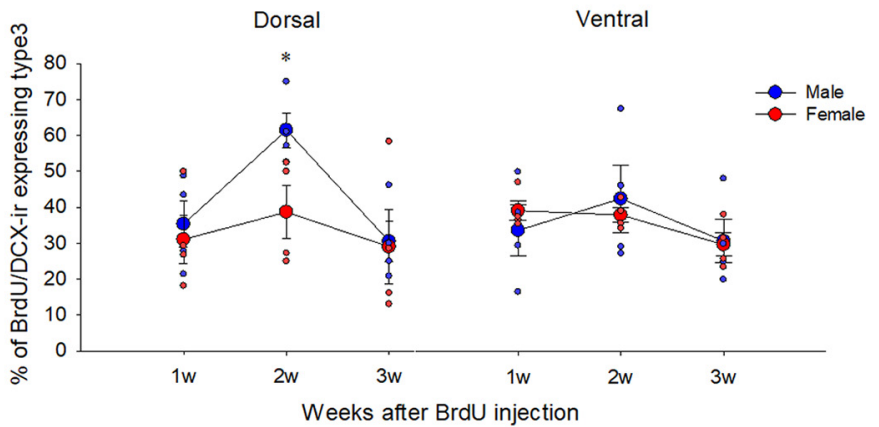

Figure 5. Sex differences in the maturation rate of adult-born neurons in the dentate gyrus (DG) (BrdU/DCX). A, Photomicrographs of BrdU (red)/DCX (green) taken from male young adult rat at $24 \mathrm{~h}$ (left; $60 \times$ objective lens) and $2 \mathrm{w}$ (right; $40 \times$ objective lens) group. $\boldsymbol{B}$, Mean $( \pm$ SEM) percentages of BrdU-ir cells that express DCX. There was no significant sex difference in the percentage of BrdUir cells that co-express DCX. C, Mean ( \pm SEM) percentages of BrdU/DCX-ir cells that had a type-C morphologic phenotype. a priori comparisons showed that male adult rats had a greater percentage of BrdU/DCX-ir cells that showed the type-C morphologic phenotype at $2 \mathrm{w}$ compared with female adult rats in the dorsal DG; $*$ indicates a significant sex difference $(p<0.05)$. All animals were age-matched and received BrdU injection at 10 weeks old. h-hours, w-weeks, BrdU-bromodeoxyuridine, DCX- doublecortin, irimmunoreactive.

\section{Male adult-born dentate granule cells mature faster compared with female adult-born dentate granule cells}

We found that adult born neurons mature faster in males than in females, with males showing a rapid increase in the percentage of BrdU-ir cells that expressed $\mathrm{NeuN}$ at two weeks. Although previous studies did not directly compare the sexes, they are consistent with our results (Brown et al., 2003; Snyder et al., 2009). These studies showed that in male rats, $65-75 \%$ of BrdU-ir cells expressed NeuN two weeks after BrdU injection (Snyder et al., 2009), whereas a separate study found in female rats $<10 \%$ of BrdU-ir cells expressed NeuN at two weeks after BrdU injection (Brown et al., 2003). Sex differences in the maturation time course of new neurons may be due to sex differences in the neural activity of the hippocampal network. Maturation of adult-born neurons is accelerated by electrophysiological activity in the hippocampus (Piatti et al., 2011), and cFos expression in the dorsal CA3 of hippocampus is greater in males compared with females in response to a Morris water maze task and radial arm maze task (Yagi et al., 2016, 2017). However, in the same studies, females show greater activation of zif268 in the dorsal CA3 compared with males, which is inconsistent with the interpretation of greater activity in the hippocampus accounting for the sex differences in maturation timelines. Another possible explanation for the higher percentage of more mature adult-born neurons in males compared with females at two weeks may involve competition and/or apoptosis resulting in part from the greater attrition from one to two weeks in males, which may impact the survival rate of new neurons (Bergami and Berninger, 2012). Further research is needed 
A

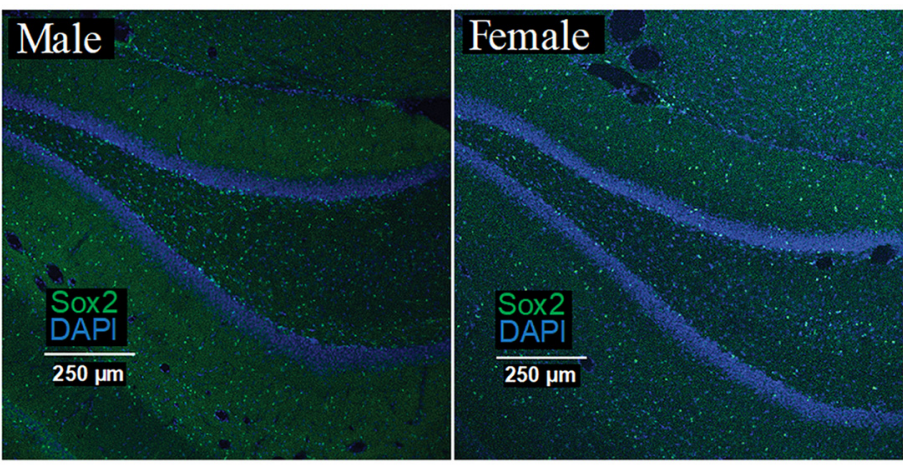

B

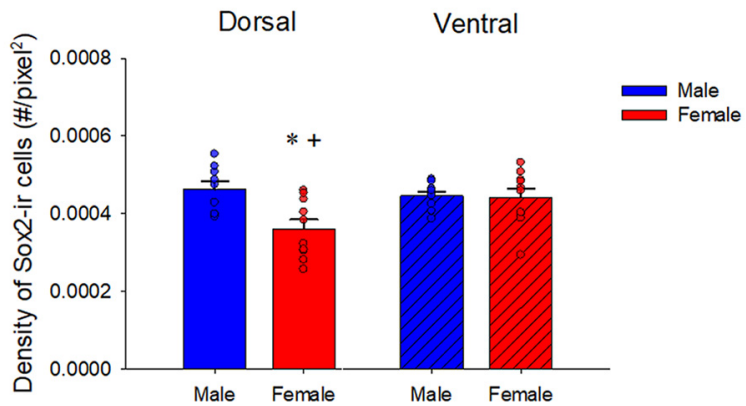

Figure 6. Sex differences in the density of neural stem cells (Sox2-ir). $\boldsymbol{A}$, Photomicrographs of Sox2 (green) with DAPI (blue) taken with $10 \times$ objective lens from a male (left) and female (right) young adult rat (11 weeks old) in the dorsal DG. $\boldsymbol{B}$, Mean ( \pm SEM) density of Sox2-ir cells: males, compared with females, had a greater density of Sox2-ir cells in the dorsal DG. The ventral DG of females, but not males, had a greater density of Sox2-ir cells compared with the dorsal DG; $*$ indicates a significant sex differences and + indicates significant a regional difference between the dorsal and ventral regions $(p<0.05)$. All animals were age-matched and received BrdU injection at 10 weeks. ir-immunoreactive, SEM-standard error of the mean, DG-dentate gyrus.

to examine the mechanisms of the sex differences in the maturation of new neurons.

\section{Males had more neural stem cells than females, whereas females showed a regional difference with more neural stem cells in the ventral, compared with dorsal, DG}

In the present study, males had a greater density of Sox2-ir cells in the dorsal DG compared with females. We also found that females had a greater density of Sox2-ir cells in the ventral compared with the dorsal region that was not observed in males. To our knowledge, neither of these findings have been reported previously. These findings suggest that within females, there is more chance of maintaining pluripotency in the ventral compared with the dorsal DG. How this might be reflected in sex differences in the functions attributed to the dorsal versus ventral hippocampus remains to be determined. However, there are some intriguing possibilities as males generally show better spatial learning (Jonasson, 2005; Voyer et al., 2017), whereas females show different stress reactions compared with males (Young and Korszun, 2010). Indeed, one study has shown that classical conditioning using shock as the unconditioned stimulus, did increase neurogenesis in the ventral DG of females but not males (Dalla et al., 2009). Our results emphasize the importance of further investigation of sex differences in the preservation of neural stem cells in the hippocampus as a potential treatment (Briley et al., 2016).

\section{The neural progenitor cell-type composition changes after mitosis with sex-dependent manner}

Consistent with past studies, we found similar percentages of Sox2-ir cells and DCX-ir cells in the progenitor proliferating pool in male rodents (Sibbe et al., 2015; Nickell et al., 2017). However, we found that females had a greater increase in the percentages of BrdU-ir cells co-expressing DCX between two and 24 hours after mitosis whereas males did not exhibit any significant change between these two time points. This finding suggests that the neural progenitor cell-type composition within the actively dividing pool in females changes after each cell division more so than in males. It also suggests that early on in division, the daughter cells proceed more rapidly through the neuronal cell lineage in females compared with males. This finding may in part explain the ability of females to compensate for the lower levels of cell proliferation to end up with a similar number of new neurons at three weeks compared with males. More studies are needed to examine sex differences in the timeline and mechanism of the transition of proliferating progenitors to new neurons for a comprehensive understanding of the regulation of neural progenitor cell pool in males and females. 
A
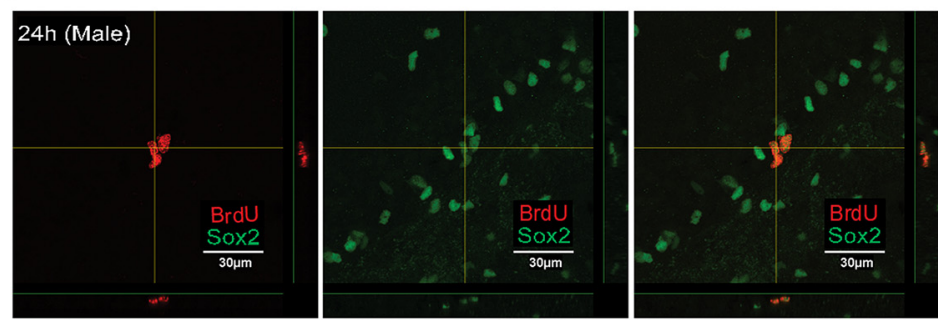

B
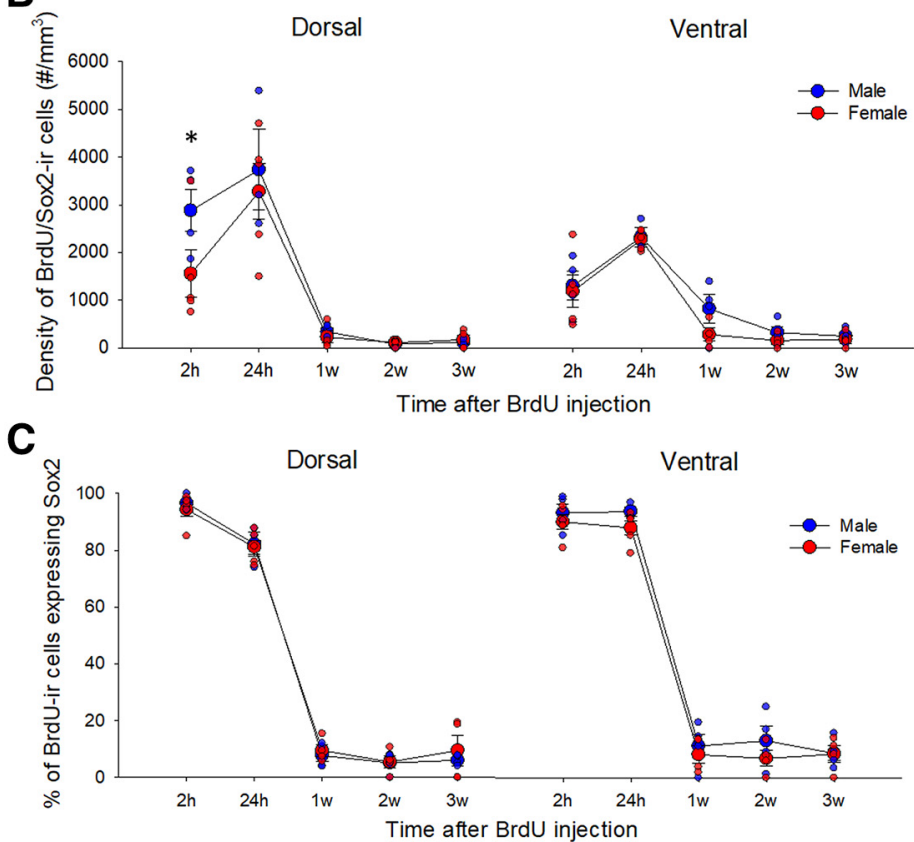

Figure 7. Sex differences in BrdU/Sox2-ir cells across time points. A, Photomicrographs of BrdU (left; red)/Sox2-ir (center; green) cells and merged images (right), taken from a male young adult rat in $24 \mathrm{~h}$ group. $\boldsymbol{B}$, Mean ( \pm SEM) density of BrdU-ir cells that express Sox2; a priori comparisons showed that male, compared with female, young adult rats had a greater density of BrdU-ir cells that co-expressed Sox2 in the dorsal DG at $2 \mathrm{~h}$ after BrdU injection; * indicates a significant sex difference $(p<0.05)$. $\mathbf{C}, \mathrm{Mean}$ $( \pm$ SEM) percentage of BrdU-ir colabelled with Sox2 at each timepoint. There was a greater percentage of colabelled cells at the 2 and $24 \mathrm{~h}$ timepoint than all other timepoints in the dorsal and ventral DG and in the dorsal DG $2 \mathrm{~h}$ timepoint had more than the $24 \mathrm{~h}$ timepoint. all ps $<0.003$ ). All animals were age-matched and received BrdU injection at 10 weeks old. BrdU-bromodeoxyuridine, irimmunoreactive, SEM-standard error of the mean, DG-dentate gyrus, h-hour, w-weeks.

\section{Neurogenesis in males has a different trajectory compared with females}

The present study found that males, but not females, showed substantial changes in the density of BrdU-ir cells across time points with an early increase from $24 \mathrm{~h}$ to one week followed by a substantial decrease from one to two weeks. The decrease was notable such that despite the fact that males showed greater density of one-week-old BrdU-ir cells than females, but there were no sex differences in density of older (two to three weeks) old BrdU-ir cells. Our findings are consistent with previous studies that demonstrating the same trajectory in male Sprague Dawley rats (Cameron et al., 1993; Snyder et al., 2009, 2012) and no significant sex difference in the amount of two- or three-week-old BrdU-ir cells in cage controls (Tanapat et al., 1999; Barha et al., 2011; Chow et al., 2013; but see Lee et al., 2014). Collectively, these results suggest that males and females regulate adult neurogenesis differently as males produce more new cells and show greater attrition of these new cells, whereas females produce fewer new cells which are preserved across maturation. These findings may explain why spatial learning and or estrogens given during the first week of new neuron development increases the survival of new neurons in males, but not in females (Ormerod et al., 2004; Epp et al., 2007; Chow et al., 2013; Yagi et al., 2016). Taken together, these results suggest that spatial training between one week and two weeks after production of new neurons can prevent the attrition of adult-born neurons in males but perhaps not in females.

\section{Males, compared with females, had greater cell proliferation in the DG}

Males had a greater density of Ki67-ir cells in the DG compared with females, consistent with findings in meadow voles (Galea and McEwen, 1999). In contrast a 
number of other studies have not found sex differences in cell proliferation in the DG (Lagace et al., 2007; Brummelte and Galea, 2010; Barha et al., 2011; Spritzer et al., 2017). However, these inconsistences may be related to estrous cycle, as only proestrous females show greater cell proliferation than male rats (Tanapat et al., 1999), although this effect has not always been noted (Lagace et al., 2007). None of the females in the Ki67 analysis were in proestrus and thus, we would expect lower levels of cell proliferation in these females. Consistent with our Ki67 results we also see increased BrdU-ir cells at 2 hours in males compared with females, but no differences at 24 hours, which likely has to do with the population that Ki67 labels versus the pulsatile BrdU (Kee et al., 2002).

\section{Conclusion}

In the present study, sex differences are noted in the neural stem cell population, cell proliferation, maturation rate and the attrition rate of adult-born neurons in the hippocampus. The trajectory of new neuron survival is dramatically different in males compared with females suggesting that the ability to influence neurogenesis within each sex may be due to the existing differences in timing and/or maturation of new neurons. Future studies should target mechanisms of these sex differences in adult neurogenesis as there are likely multiple factors involved that could profoundly affect these sex differences such as genetic (four core genotypes; Arnold and Chen, 2009), epigenetic (Sase et al., 2019), and mitochondrial functions (Biala et al., 2011) that differ between the sexes. These findings have profound implications for our understanding of adult neurogenesis in the DG, the use of therapeutics that modulate neurogenesis in the general population, and underscore the need to include both sexes in research on hippocampal neurogenesis.

\section{References}

Amador-Arjona A, Cimadamore F, Huang C-T, Wright R, Lewis S, Gage FH, Terskikh AV (2015) SOX2 primes the epigenetic landscape in neural precursors enabling proper gene activation during hippocampal neurogenesis. Proc Natl Acad Sci USA 112:E1936E1945.

Arnold AP, Chen X (2009) What does the "four core genotypes" mouse model tell us about sex differences in the brain and other tissues? Front Neuroendocrinol 30:1-9.

Banasr M, Soumier A, Hery M, Mocaër E, Daszuta A (2006) Agomelatine, a new antidepressant, induces regional changes in hippocampal neurogenesis. Biol Psychiatry 59:1087-1096.

Barha CK, Brummelte S, Lieblich SE, Galea LAM (2011) Chronic restraint stress in adolescence differentially influences hypothalamic-pituitary-adrenal axis function and adult hippocampal neurogenesis in male and female rats. Hippocampus 21:12161227.

Barker JM, Galea LAM (2008) Repeated estradiol administration alters different aspects of neurogenesis and cell death in the hippocampus of female, but not male, rats. Neuroscience 152:888-902.

Bergami M, Berninger B (2012) A fight for survival: the challenges faced by a newborn neuron integrating in the adult hippocampus. Dev Neurobiol 72:1016-1031.

Biala YN, Bogoch Y, Bejar C, Linial M, Weinstock M (2011) Prenatal stress diminishes gender differences in behavior and in expression of hippocampal synaptic genes and proteins in rats. Hippocampus 21:1114-1125.

Boldrini M, Fulmore CA, Tartt AN, Simeon LR, Pavlova I, Poposka V, Rosoklija GB, Stankov A, Arango V, Dwork AJ, Hen R, Mann JJ (2018) Human hippocampal neurogenesis persists throughout aging. Cell Stem Cell 22:589-599.e5.

Bonaguidi MA, Wheeler MA, Shapiro JS, Stadel RP, Sun GJ, Ming GL, Song H (2011) In vivo clonal analysis reveals self-renewing and multipotent adult neural stem cell characteristics. Cell 145:1142-1155.

Briley D, Ghirardi V, Woltjer R, Renck A, Zolochevska O, Taglialatela G, Micci M-A (2016) Preserved neurogenesis in non- demented individuals with AD neuropathology. Sci Rep 6:27812-27810.

Brown JP, Couillard-Després S, Cooper-Kuhn CM, Winkler J, Aigner L, Kuhn HG (2003) Transient expression of doublecortin during adult neurogenesis. J Comp Neurol 467:1-10.

Brummelte S, Galea LAM (2010) Chronic high corticosterone reduces neurogenesis in the dentate gyrus of adult male and female rats. Neuroscience 168:680-690.

Cameron HA, Mckay RDG (2001) Adult neurogenesis produces a large pool of new granule cells in the dentate gyrus. J Comp Neurol 435:406-417.

Cameron HA, Woolley CS, McEwen BS, Gould E (1993) Differentiation of newly born neurons and glia in the dentate gyrus of the adult rat. Neuroscience 56:337-344.

Cameron N, Del Corpo A, Diorio J, Mcallister K, Sharma S, Meaney MJ (2008) Maternal programming of sexual behavior and hypothalamic-pituitary-gonadal function in the female rat. PLoS One 3: e2210.

Chow C, Epp JR, Lieblich SE, Barha CK, Galea LAM (2013) Sex differences in neurogenesis and activation of new neurons in response to spatial learning and memory. Psychoneuroendocrinology 38:12361250.

Cipriani S, Ferrer I, Aronica E, Kovacs GG, Verney C, Nardelli J, Khung S, Delezoide AL, Milenkovic I, Rasika S, Manivet P, Benifla JL, Deriot N, Gressens P, Adle-Biassette H (2018) Hippocampal radial glial subtypes and their neurogenic potential in human fetuses and healthy and Alzheimer's disease adults. Cereb Cortex 28:2458-2478.

Clelland CD, Choi M, Romberg C, Clemenson GD, Fragniere A, Tyers $P$, Jessberger S, Saksida LM, Barker RA, Gage FH, Bussey TJ (2009) A functional role for adult hippocampal neurogenesis in spatial pattern separation. Science 325:210-213.

Dalla C, Papachristos EB, Whetstone AS, Shors TJ (2009) Female rats learn trace memories better than male rats and consequently retain a greater proportion of new neurons in their hippocampi. Proc Natl Acad Sci USA 106:2927-2932.

Dennis CV, Suh LS, Rodriguez ML, Kril JJ, Sutherland GT (2016) Human adult neurogenesis across the ages: an immunohistochemical study. Neuropathol Appl Neurobiol 42:621-638.

Duarte-Guterman P, Lieblich S, Wainwright SR, Chow C, Chaiton J, Watson NV, Galea LAM (2019) Androgens enhance adult hippocampal neurogenesis in males but not females in an age-dependent manner. Endocrinology 160:2128-2136.

Encinas JM, Michurina TV, Peunova N, Park J-H, Tordo J, Peterson DA, Fishell G, Koulakov A, Enikolopov G (2011) Division-coupled astrocytic differentiation and age-related depletion of neural stem cells in the adult hippocampus. Cell Stem Cell 8:566-579.

Epp JR, Spritzer MD, Galea LAM (2007) Hippocampus-dependent learning promotes survival of new neurons in the dentate gyrus at a specific time during cell maturation. Neuroscience 149:273-285.

Epp JR, Haack AK, Galea LAM (2011) Activation and survival of immature neurons in the dentate gyrus with spatial memory is dependent on time of exposure to spatial learning and age of cells at examination. Neurobiol Learn Mem 95:316-325.

Epp JR, Beasley CL, Galea LAM (2013) Increased hippocampal neurogenesis and p21 expression in depression: dependent on antidepressants, sex, age, and antipsychotic exposure. Neuropsychopharmacology 38:2297-2306. 
Falconer EM, Galea LAM (2003) Sex differences in cell proliferation, cell death and defensive behavior following acute predator odor stress in adult rats. Brain Res 975:22-36.

Fanselow MS, Dong HW (2010) Are the dorsal and ventral hippocampus functionally distinct structures? Neuron 65:7-19.

França TFA, Bitencourt AM, Maximilla NR, Barros DM, Monserrat JM (2017) Hippocampal neurogenesis and pattern separation: a metaanalysis of behavioral data. Hippocampus 27:937-950.

Galea LAM, McEwen BS (1999) Sex and seasonal differences in the rate of cell proliferation in the dentate gyrus of adult wild meadow voles. Neuroscience 89:955-964.

Gould E, Reeves A, Graziano M, Gross C (1999) Neurogenesis in the neocortex of adult primates. Science 286:548-552.

Gundersen HJ, Jensen EB (1987) The efficiency of systematic sampling in stereology and its prediction. J Microsc 147:229-263.

Hill AS, Sahay A, Hen R (2015) Increasing adult hippocampal neurogenesis is sufficient to reduce anxiety and depression-like behaviors. Neuropsychopharmacology 40:2368-2378.

Hillerer KM, Neumann ID, Couillard-Despres S, Aigner L, Slattery DA (2013) Sex-dependent regulation of hippocampal neurogenesis under basal and chronic stress conditions in rats. Hippocampus 23:476-487.

Jonasson Z (2005) Meta-analysis of sex differences in rodent models of learning and memory: a review of behavioral and biological data. Neurosci Biobehav Rev 28:811-825.

Kee N, Si S, Boonstra R, Wojtowicz JM (2002) The utility of Ki-67 and BrdU as proliferative markers of adult neurogenesis. J Neurosci Methods 115:97-105.

Kempermann G, Gast D, Kronenberg G, Yamaguchi M, Gage FH (2003) Early determination and long-term persistence of adultgenerated new neurons in the hippocampus of mice. Development 130:391-399.

Kjelstrup KG, Tuvnes FA, Steffenach HA, Murison R, Moser El, Moser MB (2002) Reduced fear expression after lesions of the ventral hippocampus. Proc Natl Acad Sci USA 99:10825-10830.

Knoth R, Singec I, Ditter M, Pantazis G, Capetian P, Meyer RP, Horvat V, Volk B, Kempermann G (2010) Murine features of neurogenesis in the human hippocampus across the lifespan from 0 to 100 years. PLoS One 5:e8809.

Kornack DR, Rakic P (1999) Continuation of neurogenesis in the hippocampus of the adult macaque monkey. Proc Natl Acad Sci USA 96:5768-5773.

Kuhn HG, Dickinson-Anson H, Gage FH (1996) Neurogenesis in the dentate gyrus of the adult rat: age-related decrease of neuronal progenitor proliferation. J Neurosci 16:2027-2033.

Lagace DC, Fischer SJ, Eisch AJ (2007) Gender and endogenous levels of estradiol do not influence adult hippocampal neurogenesis in mice. Hippocampus 17:175-180.

Lee TTY, Wainwright SR, Hill MN, Galea LAM, Gorzalka BB (2014) Sex, drugs, and adult neurogenesis: sex-dependent effects of escalating adolescent cannabinoid exposure on adult hippocampal neurogenesis, stress reactivity, and amphetamine sensitization. Hippocampus 24:280-292.

Micheli L, Ceccarelli M, D’Andrea G, Costanzi M, Giacovazzo G, Coccurello R, Caruso C, Tirone F (2018) Fluoxetine or Sox2 reactivate proliferation-defective stem and progenitor cells of the adult and aged dentate gyrus. Neuropharmacology 141:316-330.

Miller I, Min M, Yang C, Tian C, Gookin S, Carter D, Spencer SL (2018) Ki67 is a graded rather than a binary marker of proliferation versus quiescence. Cell Rep 24:1105-1112.e5.

Moreno-jiménez EP, Flor-garcía M, Terreros-roncal J, Rábano A, Cafini F, Pallas-bazarra N, Ávila J, Llorens-martín M (2019) Adult hippocampal neurogenesis is abundant in neurologically healthy subjects and drops sharply in patients with Alzheimer's disease. Nat Med 25:554-560.

Moser E, Moser MB, Andersen P (1993) Spatial learning impairment parallels the magnitude of dorsal hippocampal lesions, but is hardly present following ventral lesions. J Neurosci 13:3916-3925.

Ngwenya LB, Heyworth NC, Shwe Y, Moore TL, Rosene DL (2015) Age-related changes in dentate gyrus cell numbers, neurogenesis, and associations with cognitive impairments in the rhesus monkey. Front Syst Neurosci 9:1-16.

Nickell CRG, Peng H, Hayes DM, Chen KY, McClain JA, Nixon K (2017) Type 2 neural Progenitor cell activation drives reactive neurogenesis after binge-like alcohol exposure in adolescent male rats. Front Psychiatry 8:1-14.

Ormerod BK, Lee T-Y, Galea LA (2004) Estradiol enhances neurogenesis in the dentate gyri of adult male meadow voles by increasing the survival of young granule neurons. Neuroscience 128:645654.

Piatti VC, Davies-Sala MG, Espósito MS, Mongiat LA, Trinchero MF, Schinder AF (2011) The timing for neuronal maturation in the adult hippocampus is modulated by local network activity. $\mathrm{J}$ Neurosci 31:7715-7728.

Plümpe T, Ehninger D, Steiner B, Klempin F, Jessberger S, Brandt M, Römer B, Rodriguez GR, Kronenberg G, Kempermann G (2006) Variability of doublecortin-associated dendrite maturation in adult hippocampal neurogenesis is independent of the regulation of precursor cell proliferation. BMC Neurosci 7:77.

Rummel J, Epp JR, Galea LAM (2010) Estradiol does not influence strategy choice but place strategy choice is associated with increased cell proliferation in the hippocampus of female rats. Horm Behav 58:582-590.

Sase AS, Lombroso SI, Santhumayor BA, Wood RR, Lim CJ, Neve RL, Heller EA (2019) Sex-specific regulation of fear memory by targeted epigenetic editing of Cdk5. Biol Psychiatry 85:623-634.

Sibbe M, Kuner E, Althof D, Frotscher M (2015) Stem- and progenitor cell proliferation in the dentate gyrus of the Reeler mouse. PLoS One 10:e0119643.

Snyder JS, Hong NS, McDonald RJ, Wojtowicz JM (2005) A role for adult neurogenesis in spatial long-term memory. Neuroscience 130:843-852.

Snyder JS, Choe JS, Clifford MA, Jeurling SI, Hurley P, Brown A, Kamhi JF, Cameron HA (2009) Adult-born hippocampal neurons are more numerous, faster maturing, and more involved in behavior in rats than in mice. J Neurosci 29:14484-14495.

Snyder JS, Soumier A, Brewer M, Pickel J, Cameron HA (2011) Adult hippocampal neurogenesis buffers stress responses and depressive behaviour. Nature 476:458-461.

Snyder JS, Ferrante SC, Cameron HA (2012) Late maturation of adult-born neurons in the temporal dentate gyrus. PLoS One 7: e48757.

Sorrells SF, Paredes MF, Cebrian-Silla A, Sandoval K, Qi D, Kelley KW, James D, Mayer S, Chang J, Auguste KI, Chang EF, Gutierrez AJ, Kriegstein AR, Mathern GW, Oldham MC, Huang EJ, GarciaVerdugo JM, Yang Z, Alvarez-Buylla A (2018) Human hippocampal neurogenesis drops sharply in children to undetectable levels in adults. Nature 555:377-381.

Spritzer MD, Galea LAM (2007) Testosterone and dihydrotestosterone, but not estradiol, enhance survival of new hippocampal neurons in adult male rats. Dev Neurobiol 67:1321-1333.

Spritzer MD, Panning AW, Engelman SM, Prince WT, Casler AE, Georgakas JE, Jaeger ECB, Nelson LR, Roy EA, Wagner BA (2017) Seasonal and sex differences in cell proliferation, neurogenesis, and cell death within the dentate gyrus of adult wild-caught meadow voles. Neuroscience 360:155-165.

Steiner B, Klempin F, Wang L, Kott M, Kettenmann H, Kempermann $G$ (2006) Type-2 cells as link between glial and neuronal lineage in adult hippocampal neurogenesis. Glia 54:805-814.

Tanapat P, Hastings NB, Reeves AJ, Gould E (1999) Estrogen stimulates a transient increase in the number of new neurons in the dentate gyrus of the adult female rat. J Neurosci 19:5792-5801.

Tobin MK, Musaraca K, Disouky A, Shetti A, Bheri A, Honer WG, Kim N, Dawe RJ, Bennett DA, Arfanakis K, Lazarov O (2019) Human hippocampal neurogenesis persists in aged adults and Alzheimer's disease patients. Cell Stem Cell 24:974-982.e3.

Voyer D, Voyer SD, Saint-Aubin J (2017) Sex differences in visualspatial working memory: a meta-analysis. Psychon Bull Rev 24:307-334. 
Workman JL, Chan MYT, Galea LAM (2015) Prior high corticosterone exposure reduces activation of immature neurons in the ventral hippocampus in response to spatial and nonspatial memory. Hippocampus 25:329-344.

Yagi S, Chow C, Lieblich SE, Galea LAM (2016) Sex and strategy use matters for pattern separation, adult neurogenesis, and immediate early gene expression in the hippocampus. Hippocampus 26:87-101.
Yagi S, Drewczynski D, Wainwright SR, Barha CK, Hershorn O, Galea LAM (2017) Sex and estrous cycle differences in immediate early gene activation in the hippocampus and the dorsal striatum after the cue competition task. Horm Behav 87:6979.

Young E, Korszun A (2010) Sex, trauma, stress hormones and depression. Mol Psychiatry 15:23-28. 